\title{
Screening of Antagonistic Marine Actinomycetes: Optimization of Process Parameters for the Production of Novel Antibiotic by Amycolatopsis Alba
} var. nov. DVR D4

\author{
Venkata Ratna Ravi Kumar Dasarị*, Murali Yugandhar Nikku and Sri Rami Reddy Donthireddy \\ Center for Biotechnology, College of Engineering, Andhra University, Visakhapatnam- 530 003, India
}

\begin{abstract}
Screening of six marine sediment samples near NTPC of the Visakhapatnam (India) Coast of Bay of Bengal resulted in the isolation of 72 isolates of actinomycetes. Among these, Amycolatopsis alba var. nov. DVR D4 showed broad antibacterial activity spectra against Gram-positive and Gram-negative bacteria; and produced antibacterial metabolite extracellulary under submerged fermentation conditions. The chemical and physical process parameters affecting the production of the antibiotic were optimized. The maximum antibiotic activity was obtained with the optimized production medium containing D-glucose, $2.0 \% \mathrm{w} / \mathrm{v}$; malt extract, $4.0 \% \mathrm{w} / \mathrm{v}$; yeast extract, $0.4 \% \mathrm{w} / \mathrm{v}$; dipotassium hydrogen phosphate, $0.5 \% \mathrm{w} / \mathrm{v}$; sodium chloride, $0.25 \% \mathrm{w} / \mathrm{v}$; zinc sulphate, $0.004 \% \mathrm{w} / \mathrm{v}$; calcium carbonate, $0.04 \% \mathrm{w} / \mathrm{v}$; with inoculum volume of $5.0 \% \mathrm{v} / \mathrm{v}$ at $6.0 \mathrm{pH}, 28^{\circ} \mathrm{C}$ incubation temperature, $220 \mathrm{rpm}$ and for $96 \mathrm{~h}$ incubation.
\end{abstract}

Keywords: Screening; Optimization; Submerged fermentation; Amycolatopsis alba; Antibacterial activity; Minimum inhibitory concentration

\section{Introduction}

The microorganisms especially bacteria and actinomycetes are virtually unlimited sources of novel compounds with many therapeutic applications. Actinomycetes among them hold a prominent position due to diversity and proven ability to produce new structures. Actinomycetes are widely distributed in terrestrial and aquatic ecosystems. Especially in soil, actinomycetes play a crucial role in the recycling of refractory biomaterials by decomposing complex mixtures of polymers in dead plant, animal and fungal materials and capable of producing several secondary metabolites [1]. But the rate of discovery of new compounds from terrestrial actinomycetes has decreased, whereas the rate of re-isolation of known compounds has increased [2].Thus, it is crucial that new groups of actinomycetes from pristine habitats need to be explored as sources of novel bioactive secondary metabolites.

Actinomycetes play a significant role among the marine bacterial communities, because of its diversity and ability to produce novel bioactive compounds of high commercial and therapeutic value $[3,4]$ Marine ecosystem still an untapped source of microbial diversity and marine microbes are particularly attractive because they have not been extensively exploited as their terrestrial counterparts; and high potency required for bioactive compounds to be effective in the marine environment, due to the dilution effect of seawater. Most of the marine bioactive compounds that have been successfully screened and isolated; and structurally elucidated so far originated from microorganisms, especially from bacteria. It is estimated that less than $1 \%$ of potentially useful chemicals from marine environment has been screened so far, with microbial products especially bioactive compounds representing approximately $1 \%$ of the total number [5].

As innovative methodologies in current screening programmes, actinomycetes with unique morphology and / or physiology have been targeted and isolation methods for them have been developed. These isolated have then been exposed to non-conventional as well as conventional cultural conditions to induce antibiotic production.
Apart from the cultural conditions (inoculum age, inoculum volume) of the organism, fermentation medium has profound effect on product formation directly or indirectly. Lower concentration of nutrients may lead to poor growth and poor yields because of under nutrition. High concentrations may have a deleterious effect on growth. Catabolite repression and toxicity may be observed. To satisfy such requirement, medium should contain a judicious combination of various nutrients (mainly few inorganic salts, carbon and nitrogen source, water, etc.) at concentrations that favors the growth of organism and product formation.

In the present study, it is decided to screen marine sediment samples from shore area (Bay of Bengal: an arm of Indian Ocean) at NTPC, Visakhapatnam, India for the isolation of antagonistic actinomycetes and to optimize the process parameters for the maximum production of antibacterial metabolite under submerged fermentation.

\section{Materials and Methods}

\section{Collection of samples}

A total of six sediment samples from Bay of Bengal (NTPC area, Visakhapatnam, India) were collected by grab sampler and stored in sterile containers for the systematic screening of actinomycetes. About $50 \mathrm{~g}$ of each sample was collected from different places (at different distances and different depths) at NTPC area.

*Corresponding author: Venkata Ratna Ravi Kumar Dasari, Center fo Biotechnology, College of Engineering, Andhra University, Visakhapatnam- 530 003, India, E-mail: ravidvr@gmail.com

Received November 07, 2011; Accepted December 07, 2011; Published December 09, 2011

Citation: Venkata Ratna Ravi Kumar D, Murali Yugandhar N, Sri Rami Reddy D (2011) Screening of Antagonistic Marine Actinomycetes: Optimization of Process Parameters for the Production of Novel Antibiotic by Amycolatopsis Alba var. nov. DVR D4. J Microbial Biochem Technol 3: 092-098. doi:10.4172/19485948.1000058

Copyright: (c) 2011 Venkata Ratna Ravi Kumar D, et al. This is an open-access article distributed under the terms of the Creative Commons Attribution License, which permits unrestricted use, distribution, and reproduction in any medium, provided the original author and source are credited 
Citation: Venkata Ratna Ravi Kumar D, Murali Yugandhar N, Sri Rami Reddy D (2011) Screening of Antagonistic Marine Actinomycetes: Optimization of Process Parameters for the Production of Novel Antibiotic by Amycolatopsis Alba var. nov. DVR D4. J Microbial Biochem Technol 3: 092-098. doi:10.4172/1948-5948.1000058

\section{Screening and isolation of actinomycetes}

Marine sediment samples were stored at $4^{\circ} \mathrm{C}$ until isolation. Actinomycetes are isolated by plating out the samples in proper dilutions. Actinomycetes colonies can easily be distinguished on the plate from those of fungi and true bacteria. They are often compact, leathery giving a conical appearance and have a dry surface.

About $1 \mathrm{gm}$ of each of the above sample was taken in a $250 \mathrm{ml}$ conical flask containing $100 \mathrm{ml}$ of sterile water and was kept on a rotary shaker for 15 minutes. The suspension was serially diluted up to $10^{-6}$ level. Isolation was carried out on starch casein agar (SCAsoluble starch, 10.0g; vitamin free casein, $0.3 \mathrm{~g} ; \mathrm{KNO}_{3}, 2.0 \mathrm{~g} ; \mathrm{NaCl}$, $2.0 \mathrm{~g} ; \mathrm{K}_{2} \mathrm{HPO}_{4}, 2.0 \mathrm{~g} ; \mathrm{MgSO}_{4} .7 \mathrm{H}_{2} \mathrm{O}, 0.05 \mathrm{~g} ; \mathrm{CaCO}_{3}, 0.02 \mathrm{~g} ; \mathrm{FeSO}_{4} .7 \mathrm{H}_{2} \mathrm{O}$, $0.01 \mathrm{~g}$; agar, 20.0g; sterilized natural aged sea water, $1.0 \mathrm{~L} ; \mathrm{pH}, 7.2$; supplemented with rifampicin $2.5 \mu \mathrm{g} / \mathrm{ml}$ and cycloheximide $75 \mu \mathrm{g} / \mathrm{ml}$ to inhibit bacterial and fungal contamination, respectively) plates, which had been seeded with a sediment sample suspension of $1.0 \mathrm{ml}$ each and incubated at $28^{\circ} \mathrm{C}$ for 14 days [6]. After 14 days, actinomycete colonies were carefully isolated from different plates avoiding any bacterial or fungal contamination. The actinomycete colonies, which appeared different from one another to the naked eye (surface texture), were transferred and incubated at $28^{\circ} \mathrm{C}$ for 2 weeks; and maintained on yeast extract malt extract (YEME - yeast extract, 4.0g; malt extract, 10.0g; D-glucose, 4.0g; agar, 20.0g; distilled water, $1.0 \mathrm{~L} ; \mathrm{pH}, 7.2$ ) slants at $4^{\circ} \mathrm{C}$ and as a glycerol suspension $(20 \% \mathrm{v} / \mathrm{v})$ at $-20^{\circ} \mathrm{C}$ [7].

The isolates were pooled together and cultures which appeared identical to naked eye in respect of color of aerial mycelium, reverse color, soluble pigment and colony texture were eliminated. A total of 72 actinomycetes were isolated from the above samples.

\section{Antimicrobial activity studies}

The following test organisms used in the study were procured from the National Collection of Industrial Microorganisms (NCIM), National Chemical Laboratory (NCL), Pune, India and Microbial Type Culture Collection (MTCC), Institute of Microbial Technology (IMTECH), Chandigarh, India: Aeromonas formicans NCIM 2319, Bacillus licheniformis NCIM 2051, Bacillus pumilus NCIM 2327, Bacillus subtilis NCIM 2439, Brevibacterium divericatum NCIM 2634, Brevibacterium roseum NCIM 2270, Brevibacterium saccharolyticum NCIM 2238, Escherichia coli NCIM 2067, Proteus vulgaris NCIM 2027, Pseudomonas fluorescens NCIM 2141, Pseudomonas taetrolens MTCC 1612, Staphylococcus aureus NCIM 5021 and Streptomyces griseus NCIM 2622.

Cross-streak method: The marine actinomycete isolates were screened for antibacterial activity by cross streak method on nutrient agar plates. Each plate was streaked with each isolate at the center of the plate and incubated at $28^{\circ} \mathrm{C}$ for 5 days. After 5 days test organisms were streaked perpendicular to the growth of the actinomycete isolates. The intensity of inhibition against the test bacteria of each isolated was noted after $24 \mathrm{~h}$ of incubation. Plates with the same medium without inoculation of actinomycetes but with simultaneous streaking of test organisms were maintained as control.

Selection of promising isolates using cup-plate method: Among the active isolates resulted in the preliminary screening programme by cross-streak method, promising isolates were selected for extracellular antibiotic production studies by submerged cultivation using cup-plate method. The most sensitive organism which gave sharp inhibition zone was selected as test organisms for the selected isolate.

Well sporulated isolates (7-10 days old) were used for the antibiotic production studies. Five $\mathrm{ml}$ of sterile water was transferred aseptically into each slant and the growth of the isolate on the surface of the medium was scrapped with sterile inoculating needle and transferred each into $45 \mathrm{ml}$ of production medium (composition: sucrose, 20.0g; malt extract, 10.0g; yeast extract, $4.0 \mathrm{~g}$; dipotassium hydrogen phosphate, 5.0g; sodium chloride, $2.5 \mathrm{~g}$; zinc sulphate, $0.04 \mathrm{~g}$; calcium carbonate, $0.4 \mathrm{~g} ; 1.0 \mathrm{~L}$ sterile distilled water with $\mathrm{pH} 7.0$ ) and incubated at $28^{\circ} \mathrm{C}$ on a rotary shaker at $220 \mathrm{rpm}$ for 5 days. Then the samples were collected into sterile centrifuge tubes and centrifuged at $4000 \mathrm{rpm}$ for $10 \mathrm{~min}$, at $8^{\circ} \mathrm{C}$ and clear culture filtrate was separated. The clear supernatant was used for antibiotic assay using cup-plate method. The antibacterial activity against the bacterial organisms was tested on nutrient agar medium.

The molten sterile nutrient agar medium was cooled to $40-45^{\circ} \mathrm{C}$, inoculated with test organism, mixed thoroughly, poured into sterile petri plates and allowed to settle. Cups were made using sterile cork borer. The clear supernatant fermentation broth was added to each cup $(50 \mu \mathrm{l})$ by using micropipette. The procedure was repeated for all the promising isolates and each isolate was tested for antibacterial activity. The plates were kept in the refrigerator for about $2 \mathrm{~h}$ for antibiotic diffusion and then incubated at $37^{\circ} \mathrm{C}$. After $24 \mathrm{~h}$ the inhibition zones were recorded. Experiments were conducted in triplicate and results were the average of the three default trails.

\section{Taxonomy and genotypic characterization}

The cultural and morphology properties were examined by using standard procedures [8] and procedures of Williams et al. [9] after growth on YEME Agar for 7-10 days at $28^{\circ} \mathrm{C}$. Phenotypic tests were carried out following the procedures of Goodfellow et al. [10] and Gordon et al. [11]. Chemotaxonomic characters were determined as described previously [12,13-17]

The genotypic characterization (16s rDNA analysis) was carried out following the standard methods $[18,19]$. The $\mathrm{G}+\mathrm{C}$ content of the DNA was determined using the Genetool software with PGEM as the control. The amplified product was sequenced using universal primers (5' to 3') fD2 (ccgaattcgtcgacaac-AGAGTTTGATCATGGCTCAG) and rP1 (cccgggatccaagcttACGGTTACCTTGTTACGACTT). The nucleotide sequence was obtained by processing DNA sequencing samples using ABI 3130 (4 capillary) electrophoresis instruments. The resultant $16 \mathrm{~S}$ rDNA sequence was aligned using Gene Tool Lite version 1.0 software program against corresponding sequences retrieved from the Gene bank database. The tree making algorithm used was Neighbor joining [20] with Max Seq diff of 0.75. The phylogenetic tree was constructed (newick format) using Tree view software.

\section{Submerged fermentation studies}

Selection of suitable marine actinomycete isolate: From the screening experiments, isolate showing significant broad spectrum antibacterial activity against the tested bacterial organisms was selected for further studies. The selected isolate (DVR D4) was sub-cultured on YEME medium agar slants incubated at $28^{\circ} \mathrm{C}$ for 7 days and used accordingly.

Selection of inoculum medium: The following two media (IM1 and IM2) were tested

IM1 (organic medium) composition: beef extract, 3.0g; tryptone, 5.0g; yeast extract, $5.0 \mathrm{~g}$; dextrose, $1.0 \mathrm{~g}$; potato starch, $24.0 \mathrm{~g}$; calcium carbonate, $2.0 \mathrm{~g}$; distilled water, $1.0 \mathrm{~L} ; \mathrm{pH}, 7.0$.

IM2 (complex medium) composition: soyabean meal, 10.0g; corn 
Citation: Venkata Ratna Ravi Kumar D, Murali Yugandhar N, Sri Rami Reddy D (2011) Screening of Antagonistic Marine Actinomycetes: Optimization of Process Parameters for the Production of Novel Antibiotic by Amycolatopsis Alba var. nov. DVR D4. J Microbial Biochem Technol 3: 092-098. doi:10.4172/1948-5948.1000058

steep solids, 10.0g; glucose, 5.0g; calcium carbonate, 5.0g; distilled water, 1.0L; pH, 7.0.

The spore suspension of the selected isolate (DVR D4) was prepared by scraping with $5.0 \mathrm{ml}$ of sterile distilled water and transferred to 45 $\mathrm{ml}$ of each medium contained in $250 \mathrm{ml}$ conical flasks and incubated on a rotary shaker at $28^{\circ} \mathrm{C}$ and $220 \mathrm{rpm}$ for $48 \mathrm{~h}$. A $10 \% \mathrm{v} / \mathrm{v}$ level of inoculum was transferred to the production medium (composition: sucrose, 20.0g; malt extract, 10.0g; yeast extract, 4.0g; dipotassium hydrogen phosphate, $5.0 \mathrm{~g}$; sodium chloride, $2.5 \mathrm{~g}$; zinc sulphate, $0.04 \mathrm{~g}$; calcium carbonate, $0.4 \mathrm{~g} ; 1.0 \mathrm{~L}$ sterile distilled water with $\mathrm{pH} 7.0$ ). The fermentations were run at $28^{\circ} \mathrm{C}$ for 5 days on a rotary shaker at $220 \mathrm{rpm}$ and the antibacterial activity was studied with the clear centrifuged broth samples at the end of fermentation by cup-plate method. The productivity of the selected isolate was confirmed; and the best inoculum medium was selected and used for further studies.

Selection of production medium: The following two media (PM1 and PM2) were tested:

PM1 composition: sucrose, 20.0g; malt extract, 10.0g; yeast extract, $4.0 \mathrm{~g}$; dipotassium hydrogen phosphate, $5.0 \mathrm{~g}$; sodium chloride, $2.5 \mathrm{~g}$; zinc sulphate, $0.04 \mathrm{~g}$; calcium carbonate, $0.4 \mathrm{~g}$; sterile distilled water, 1.0L; $\mathrm{pH}, 7.0$.

PM2 composition: soyabean meal, 10.0g; Corn steep solids, 5.0g; Soluble starch, 10.0g; Dextrose, 5.0g; Calcium carbonate, 7.0g; Distilled water, 1.0L; pH, 7.2.

The spore suspension of the selected isolate (DVR D4) was prepared by scraping with $5.0 \mathrm{ml}$ of sterile distilled water and transferred to 45 $\mathrm{ml}$ of selected inoculum medium (IM2) contained in $250 \mathrm{ml}$ conical flasks; and incubated on a rotary shaker at $28^{\circ} \mathrm{C}$ for $48 \mathrm{~h}$. A $10 \% \mathrm{v} / \mathrm{v}$ level of inoculum was transferred to the production mediums (PM1 and $\mathrm{PM} 2$ ). The fermentations were run at $28^{\circ} \mathrm{C}$ for 5 days on a rotary shaker at $220 \mathrm{rpm}$ and the antibacterial activity was studied with the clear centrifuged broth samples at the end of fermentation by cup-plate method. The best production medium (PM1) was selected and used for further studies.

\section{Optimization studies}

Optimization is a process of determination of ideal conditions for the growth of the organism and formation of metabolites by the organism. The fermentation product yield is not only dependent on the nature of the strain and the composition of the medium but also on the cultural conditions [21-32]. The following important parameters are investigated: 1) effect of carbon source, 2) effect of nitrogen source, 3) effect of $\mathrm{pH}, 4$ ) effect of inoculum volume and 5) effect of incubation time. The experiments were carried out in such a way that the parameter optimized in one experiment was maintained in the subsequent investigation. Experiments were conducted in triplicate and results were expressed as mean \pm SD (standard deviation).

Effect of carbon source: The different carbon sources used in this study are: sucrose, D-glucose, starch, lactose and fructose. Each carbon source was incorporated at $1.0 \% \mathrm{w} / \mathrm{v}$ level into the production medium (PM1) in place of sucrose. A $10 \% \mathrm{v} / \mathrm{v}$ level of inoculum (IM2) was transferred to the basal production medium and the fermentations were run at $28^{\circ} \mathrm{C}$ for 5 days on a rotary shaker at $220 \mathrm{rpm}$. At the end of fermentation, the centrifuged broth samples were evaluated for their antibacterial activity by cup-plate method using Bacillus pumilus and Aeromonas formicans as test organisms. As D-glucose was found to be the best carbon source for the antibiotic production, it is suggested to study the effect of various concentrations of $\mathrm{D}$-glucose on antibiotic production.

Determination of optimum concentration of D-glucose: The following concentrations were investigated to determine the optimum concentration of $\mathrm{D}$-glucose for maximum antibiotic production $(\% \mathrm{w} / \mathrm{v}): 1.0,2.0,3.0,4.0,5.0,6.0,7.0$ and 8.0. Each of the above concentration was incorporated into the basal production medium with a $10 \% \mathrm{v} / \mathrm{v}$ level inoculum and incubated at $28^{\circ} \mathrm{C}$ for 5 days at 220 $\mathrm{rpm}$. The antimicrobial activity was determined as described earlier.

Effect of nitrogen source: The following nitrogen sources were tested: beef extract, tryptone, peptone, ammonium nitrate, potassium nitrate and calcium nitrate. Each nitrogen source was incorporated at $1.0 \% \mathrm{w} / \mathrm{v}$ level into the production medium (PM1) in place of malt extract. The fermentation and evaluation of their antibacterial activities were carried out as per the general procedure. Among the nitrogen sources employed, malt extract was found to be the best nitrogen source for the antibiotic production. Hence it is selected to study the effect of various concentrations of malt extract on antibiotic production.

Determination of optimum concentration of malt extract : The following concentrations of malt extract were investigated to determine the optimum concentration for maximum antibiotic production $(\% \mathrm{w} / \mathrm{v}): 1.0,2.0,3.0,4.0$ and 5.0. Each of the above concentration was incorporated into the basal production medium and fermentations were conducted. The antimicrobial activity was determined as described earlier.

Effect of initial $\mathbf{p H}$ : The optimum initial $\mathrm{pH}$ of the medium is one the factor effecting growth, product formation of microorganisms and the character of their metabolism. The $\mathrm{H}^{+}$or $\mathrm{OH}^{-}$ion concentrations may have direct effort on the cell or it may act indirectly. The effect of initial $\mathrm{pH}$ of the medium was studied with $\mathrm{pH}$ values 5.0, 6.0, 7.0 and 8.0. The fermentation was carried out and the antibiotic produced was assayed.

Effect of inoculum volume: In all our previous experiments, a 10 $\% \mathrm{v} / \mathrm{v}$ level of the fresh culture was used as the inoculum. In the present experiment different inoculum volumes $(\% \mathrm{v} / \mathrm{v})$ such as: $2.5,5.0,10.0$, 15.0, 20.0, 25.0 and $30.0 \%$ were used. The fermentation and evaluation of their antibacterial activities were carried out as per the general procedure.

Effect of incubation time: With all the optimized parameters, the selected isolate DVR D4 (5\%v/v, $48 \mathrm{~h}$ inoculum) was subjected to fermentation with $1.0 \mathrm{~L}$ flask containing $200 \mathrm{ml}$ production medium. The fermentation was conducted at $28^{\circ} \mathrm{C}$ for 8 days and the samples $(10$ $\mathrm{ml}$ ) were drawn at regular intervals. The $\mathrm{pH}$ and antibiotic activities were observed and optimized incubation time was determined.

\section{Results and Discussion}

\section{Screening and isolation of actinomycetes}

With an aim of isolating actinomycetes from marine environment, a total of six sediment samples from different places at NTPC, Visakhapatnam, India were collected. Actinomycetes were isolated by plating out the samples in proper dilutions on starch casein agar (SCA) medium (supplemented with rifampicin $2.5 \mu \mathrm{g} / \mathrm{ml}$ and cycloheximide $75 \mu \mathrm{g} / \mathrm{ml}$ to inhibit bacterial and fungal contamination, respectively) and incubated at $28^{\circ} \mathrm{C}$ for 14 days. After 14 days, actinomycetes colonies were carefully isolated from the SCA plates avoiding the bacterial or fungal contamination; and maintained on YEME agar slants. 
Citation: Venkata Ratna Ravi Kumar D, Murali Yugandhar N, Sri Rami Reddy D (2011) Screening of Antagonistic Marine Actinomycetes: Optimization of Process Parameters for the Production of Novel Antibiotic by Amycolatopsis Alba var. nov. DVR D4. J Microbial Biochem Technol 3: 092-098. doi:10.4172/1948-5948.1000058

Actinomycetes colonies can easily be distinguished on the plate from those of fungi and true bacteria. They are often compact, leathery giving a conical appearance and have a dry surface. The isolates were pooled together and cultures which appeared identical to naked eye in respect of color of aerial mycelium, reverse color, soluble pigment and colony texture were eliminated. Altogether 72 actinomycetes in total were isolated from the six marine sediment samples and were designated as A batch (A1-A12), B batch (B1-B12), E batch (E1-E14), F batch (F1-F9), O batch (O1-O12) and D batch (D1-D13).

\section{Determination of antibacterial activity of isolated marine actinomycetes}

Cross-streak method: All the 72 marine actinomycete isolates were screened for antibacterial activity by cross streak method on nutrient agar plates. Each plate was streaked with each isolate at the center of the plate and incubated at $28^{\circ} \mathrm{C}$ for 5 days. After 5 days, bacterial test organisms were streaked perpendicular to the growth of the actinomycete isolates. Plates with the same medium without inoculation of actinomycetes but with simultaneous streaking of test organisms were maintained as control. The intensity of inhibition against the test bacteria of each actinomycete isolate was noted after 24 $h$ of incubation (Tables S1-S6).

From the cross streak method screening for antibacterial spectra of the 72 isolated marine actinomycetes, 55 isolates showed activity against both Gram-positive and Gram-negative bacteria, 9 isolates showed activity only against Gram-positive bacteria and 8 isolates did not posses any antibacterial activity.

Selection of promising isolates using cup-plate method: Among the 55 marine sediment actinomycete isolates that showed activity against both Gram-positive and Gram-negative bacteria in the preliminary screening programme by cross streak method; 26 isolates showing significant intensity of inhibition were selected for extracellular antibiotic production studies by submerged fermentation using cup-plate method.

Well sporulated isolates (7-10 days old) were used for the antibiotic production studies. Five $\mathrm{ml}$ of sterile water was transferred aseptically into each slant and the growth of the isolate on the surface of the medium was scrapped with sterile inoculating needle and transferred each into $45 \mathrm{ml}$ of production medium and incubated at $28^{\circ} \mathrm{C}$ on a rotary shaker at $220 \mathrm{rpm}$ for 5 days. Then the samples were collected into sterile centrifuge tubes and centrifuged at $4000 \mathrm{rpm}$ for $10 \mathrm{~min}$, at $8^{\circ} \mathrm{C}$ and clear culture filtrate was separated. The clear supernatant was used for antibiotic assay using cup-plate method against the test bacterial organisms on nutrient agar medium.

The molten sterile nutrient agar medium was cooled, inoculated with test organism and poured into sterile petri plates and allowed to settle. Cups were made using sterile cork borer and the clear supernatant fermentation broth of each isolate was added to each cup $(50 \mu \mathrm{l})$ by using micropipette. The procedure was repeated for all the promising isolates and each isolate was tested for antibacterial activity. The plates were incubated at $37^{\circ} \mathrm{C}$ for $24 \mathrm{~h}$ and the inhibition zones were recorded (Table S7). Experiments were conducted in triplicate and results were the average of the three default trails.

From the results of antibacterial activities of the 26 selected marine sediment isolates by cup-plate method, isolate DVR D4 showed potential antibacterial activity against the both Gram-positive and

\section{Gram-negative bacteria.}

\section{Taxonomy and Genotypic characterization: Identification of selected marine isolate}

The isolated bioactive actinomycete strain DVR D4 was aerobic, non-motile, Gram-positive, non-acid filamentous, differentiated into substrate; abundant white aerial mycelium was produced and it also fragments into cylindrical elements. Cylindrical, smooth spores are formed with typical cobweb morphology. The GenBank accession number for the $16 \mathrm{~S}$ rDNA sequence of strain DVR D4 is JN872327. It grows on $2 \% \mathrm{NaCl}$ at $28^{\circ} \mathrm{C}$ and in $\mathrm{pH}$ range of 5.2 to 10.0 . It was positive for urease, catalase and liquefaction of gelatin but negative for indole, oxidase, hydrolysis of starch and casein, utilization of citrate, $\mathrm{H}_{2} \mathrm{~S}$ production and nitrate reduction. Acid was produced from the following carbohydrates: galactose, glucose, mannitol, xylose and fructose. Acid was not produced from the arabinose, raffinose, salicin, sucrose, rhamnose and meso-inositol. Studies indicated that this actinomycete belongs to the Amycolatopsis genus. A detailed survey of literature and the genotypic characterization revealed that it is a strain variety of A. alba and designated as A. alba var. nov DVR D4. A. alba isolation from marine environment was reported for the first time and also this was the first bioactive strain of $A$. alba isolated in India. The complete results were reported in our previously published articles [33].

\section{Optimization studies}

Selection of suitable inoculum medium for antibiotic production under submerged fermentation by Amycolatopsis alba var. nov DVR D4: To select the best inoculum medium for antibiotic production by submerged fermentation using marine actinomycete isolate Amycolatopsis alba var. nov DVR D4, two different inoculum media's IM1 and IM2 were evaluated. The results indicate that inoculum medium IM2 supported maximum antibiotic yield (Table 1).

Selection of suitable production medium for antibiotic production under submerged fermentation by Amycolatopsis alba var. nov DVR D4: To select the best production medium for antibiotic production by submerged fermentation using marine actinomycete isolate Amycolatopsis alba var. nov DVR D4, two different production media's PM1 and PM2 were evaluated. The results indicate that production medium PM1 supported maximum antibiotic yield (Table $2)$; hence it was used in further studies.

The inoculum medium IM2 and production medium PM1 were selected and used for all our further studies using Amycolatopsis alba var. nov DVR D4.

Effect of carbon source: The exogenous addition of various carbon sources to media may improve cell growth and antibiotic production $[5,34,35]$. To determine the effect of other carbon sources on antibiotic production, different carbon sources were tested which include sucrose, D-glucose, starch, lactose and fructose. Each carbon source was incorporated at $1.0 \% \mathrm{w} / \mathrm{v}$ level into the production medium (PM1)

\begin{tabular}{|l|l|l|}
\hline Inoculum medium & \multicolumn{2}{|l|}{ Antibacterial activity (inhibition zone in $\mathbf{m m}$ ) } \\
\hline & Bacillus pumilus & Aeromonas formicans \\
\hline IM1 & 11 & 12 \\
\hline IM2 & 13 & 16 \\
\hline
\end{tabular}

Table 1: Selection of suitable inoculum medium for antibiotic production by cup plate method. 
Citation: Venkata Ratna Ravi Kumar D, Murali Yugandhar N, Sri Rami Reddy D (2011) Screening of Antagonistic Marine Actinomycetes: Optimization of Process Parameters for the Production of Novel Antibiotic by Amycolatopsis Alba var. nov. DVR D4. J Microbial Biochem Technol 3: 092-098. doi:10.4172/1948-5948.1000058

in place of sucrose. A $10 \% \mathrm{v} / \mathrm{v}$ level of inoculum was transferred to the basal production medium and the fermentations were run at $28^{\circ} \mathrm{C}$ for 5 days on a rotary shaker at $220 \mathrm{rpm}$. At the end of fermentation, centrifuged broth samples were evaluated for their antibacterial activity by cup-plate method using Bacillus pumilus and Aeromonas formicans as test organisms.

Glucose has commonly been observed to repress the synthesis of enzymes that are required for antibiotic production. But that does not appear to happen in this case. The results indicate that $A$. alba var. nov DVR D4 showed highest antibacterial activity, when D-glucose was supplemented in the medium. Addition of other sources to the medium also favored the antibacterial production but the activity was less when compared with D-glucose (Table 3). The result was similar with the reported literature where glucose was found to be the suitable carbon source for growth of microorganism as well as for the production of bioactive metabolite [36,37]. In contrary, catabolite repression exerted by $\mathrm{D}$-glucose caused a negative action on gentamycin synthesis by Micromonospora purpurea [38].

Determination of optimum concentration of D-glucose: As D-glucose was found to be the suitable carbon source for the antibiotic production, the effect of various concentrations (range - 1.0, 2.0, 3.0, $4.0,5.0,6.0,7.0$ and $8.0 \% \mathrm{w} / \mathrm{v}$ ) of $\mathrm{D}$-glucose on antibiotic production were studied. Each of the above concentration was incorporated into the basal production medium and incubated with a $10 \% \mathrm{v} / \mathrm{v}$ level inoculum and incubated at $28^{\circ} \mathrm{C}$ for 5 days at $220 \mathrm{rpm}$. The antimicrobial activity was determined as described earlier.

The results indicate that supplementation of $2.0 \% \mathrm{w} / \mathrm{v}$ D-glucose into the production medium was found to be the optimum concentration for maximum antibacterial activity and variation of this source concentration on either sides showed reduced antibacterial activity (Table 4). Similar observation was reported by Syed et al.[39] that $2.0 \% \mathrm{w} / \mathrm{v} \mathrm{D}$-glucose was found to be the optimum concentration for maximum antibiotic production. High concentration of glucose is generally considered as repressor of secondary metabolisms [40] and maximum cell growth rates can inhibit antimicrobial agent production [41]. A catabolic repression of secondary metabolism produced by actinomycetes during actinomycin synthesis by Streptomyces antibioticus was reported after the addition of more glucose in the medium [42].

Effect of nitrogen source: Depending on the biosynthetic pathway involved, nitrogen sources may affect antibiotic production [43]. The

\begin{tabular}{|l|l|l|}
\hline Production medium & \multicolumn{2}{|c|}{ Antibacterial activity (inhibition zone in mm) } \\
\hline & Bacillus pumilus & Aeromonas formicans \\
\hline PM1 & 14 & 17 \\
\hline PM2 & 12 & 15 \\
\hline
\end{tabular}

Table 2: Selection of suitable production medium for antibiotic production by cupplate method.

\begin{tabular}{|l|l|l|}
\hline Carbon source $\mathbf{( 1 . 0} \% w / v)$ & Antibacterial activity & (inhibition zone in $\mathbf{~ m m})$ \\
\hline & Bacillus pumilus & Aeromonas formicans \\
\hline Sucrose (control) & $14.0 \pm 0.87$ & $16.9 \pm 0.29$ \\
\hline D-glucose & $\mathbf{1 4 . 5} \pm \mathbf{0 . 5 0}$ & $\mathbf{1 9 . 0} \pm \mathbf{0 . 5 0}$ \\
\hline Starch & $9.2 \pm 0.36$ & $10.3 \pm 0.72$ \\
\hline Lactose & $11.8 \pm 1.04$ & $17.5 \pm 0.50$ \\
\hline Fructose & $13.2 \pm 0.76$ & $16.8 \pm 0.29$ \\
\hline
\end{tabular}

Table 3: Selection of suitable carbon source for antibiotic production by cup-plate method.

\begin{tabular}{|l|l|l|}
\hline D-glucose (\%w/v) & \multicolumn{2}{|l|}{ Antibacterial activity (inhibition zone in $\mathbf{m m}$ ) } \\
\hline & Bacillus pumilus & Aeromonas formicans \\
\hline 1.0 & $14.5 \pm 0.50$ & $19.0 \pm 0.50$ \\
\hline 2.0 & $\mathbf{1 6 . 5} \pm \mathbf{0 . 5 0}$ & $\mathbf{1 9 . 8} \pm \mathbf{0 . 7 6}$ \\
\hline 3.0 & $14.3 \pm 0.58$ & $15.7 \pm 0.29$ \\
\hline 4.0 & $12.8 \pm 0.76$ & $15.2 \pm 0.76$ \\
\hline 5.0 & $12.7 \pm 0.58$ & $14.3 \pm 0.58$ \\
\hline 6.0 & $10.5 \pm 0.50$ & $12.5 \pm 0.50$ \\
\hline 7.0 & $8.8 \pm 0.76$ & $11.5 \pm 0.50$ \\
\hline 8.0 & $8.5 \pm 0.50$ & $9.80 \pm 0.29$ \\
\hline
\end{tabular}

Table 4: Determination of optimum concentration of D-glucose for antibiotic production by cup-plate method.

following nitrogen sources were tested: beef extract, malt extract, tryptone, peptone, ammonium nitrate, potassium nitrate and calcium nitrate. Each nitrogen source was incorporated at $1.0 \% \mathrm{w} / \mathrm{v}$ level into the production medium in place of malt extract. The fermentation and evaluation of their antibacterial activities were carried out as per the general procedure.

Nitrogen source was an important factor for the biosynthesis of antibiotics. The results indicate that maximum antibacterial activity was observed with malt extract and all the other sources tested are poor nitrogen sources for antibacterial production (Table 5). Similar result was reported by [43].that malt extract as the best nitrogen source for the production of antibacterial metabolite by $S$. albovinaceus strain no. $10 / 2$.

Determination of optimum concentration of malt extract: The following concentrations of malt extract were investigated to determine the optimum concentration for maximum antibiotic production $(\% \mathrm{w} / \mathrm{v}): 1.0,2.0,3.0,4.0$ and 5.0. Each of the above concentration was incorporated into the basal production medium and fermentations were conducted.

The results indicate that significant antibacterial activity was increased at $4.0 \% \mathrm{w} / \mathrm{v}$ concentration of malt extract and further increase in concentration decreased the antibacterial activity (Table 6) [43] reported that $1.0 \% \mathrm{w} / \mathrm{v}$ malt extract as optimum concentration for maximum antibiotic production.

Effect of initial $\mathbf{p H}$ : The initial $\mathrm{pH}$ of the production medium is an important factor which affects the growth and antibacterial production during submerged fermentation. The hydrogen or hydroxyl ion concentration may have a direct effect on cell or it may act indirectly by varying the degree of dissociation of substances in the medium [44]. The effect of initial $\mathrm{pH}$ of the medium was studied varying the $\mathrm{pH}$ range of 5.0 to 8.0.The results indicate that the antibacterial activity increased and attained maximum with increase in the initial $\mathrm{pH}$ of the medium from 5.0 to 6.0; and further increase in $\mathrm{pH}$ reduced the antibacterial activity (Table 7). Similar result of 6.0 as optimum $\mathrm{pH}$ was reported by Jain and Pundir [44] for the production of antimicrobial metabolite by $A$. terreus. The effect of initial $\mathrm{pH}$ of the production medium on antibacterial activity was found to be very important parameter since the variation in activity was observed with the manipulation of initial $\mathrm{pH}$ of the medium.

Effect of inoculum volume : Different inoculum volume (\%v/v) such as: $2.5,5.0,10.0,15.0,20.0,25.0$ and $30.0 \%$ were used to determine the optimum inoculum volume for maximum antibiotic production. The fermentation and evaluation of their antibacterial activities were carried out as per the general procedure. 
Citation: Venkata Ratna Ravi Kumar D, Murali Yugandhar N, Sri Rami Reddy D (2011) Screening of Antagonistic Marine Actinomycetes: Optimization of Process Parameters for the Production of Novel Antibiotic by Amycolatopsis Alba var. nov. DVR D4. J Microbial Biochem Technol 3 : 092-098. doi:10.4172/1948-5948.1000058

The results indicate that manipulation of the inoculum volume concentration had significant effect on antibacterial activity. $5.0 \% \mathrm{v} / \mathrm{v}$ inoculum volume was found to be the optimum inoculum volume for maximum antibacterial activity (Table 8 ). It was important to provide an optimum inoculum level in fermentation process. As a lower inoculum may give insufficient biomass causing reduced product formation, whereas a higher inoculum may produce too much biomass leading to poor product formation [45].

Effect of incubation time: With all the optimized parameters, the selected isolate DVR D4 (5\%v/v, $48 \mathrm{~h}$ inoculum) was subjected to fermentation with $1.0 \mathrm{~L}$ flask containing $200 \mathrm{ml}$ production medium. The fermentation was conducted at $28^{\circ} \mathrm{C}$ for 8 days and the samples $(10$ $\mathrm{ml}$ ) were drawn at regular intervals. The $\mathrm{pH}$ and antibiotic activities were observed and optimized incubation time was determined.

The results indicate that a gradual increase in antibacterial activity was observed with increase in the incubation time from day 2 to day 4 and further increase in incubation time resulted in gradual decrease of antibacterial activity (Table 9). The reduction in activity after an optimum incubation might be due to a reduced growth rate resulting from rapid depletion of nutrients available to the organism. In other terms, as nutrients are exhausted and toxic products accumulate, the growth rate of the cells deviates from the maximum and eventually growth ceases as the culture enters the stationary phase. After a period of time, the culture enters the death phase and the numbers of viable cells decrease resulting in the decrease in production [46]. Similar result was reported by Abdelghani [43] and Sujatha et al.[37] that 4 days of incubation as optimum incubation time for the production of antibacterial metabolite.

\begin{tabular}{|l|l|l|}
\hline Nitrogen source $\mathbf{( 1 . 0} \% \mathbf{w} / \mathbf{v})$ & Antibacterial activity & (inhibition zone in $\mathbf{m m}$ ) \\
\hline & Bacillus pumilus & Aeromonas formicans \\
\hline Beef extract & $9.6 \pm 0.76$ & $10.6 \pm 0.50$ \\
\hline Malt extract (control) & $\mathbf{1 6 . 5} \pm \mathbf{0 . 8 7}$ & $\mathbf{2 0 . 2} \pm \mathbf{0 . 2 9}$ \\
\hline Tryptone & $9.3 \pm 0.58$ & $10.7 \pm 0.58$ \\
\hline Peptone & $9.0 \pm 1.00$ & $10.5 \pm 0.50$ \\
\hline Ammonium nitrate & $8.2 \pm 0.50$ & $9.6 \pm 0.50$ \\
\hline Potassium nitrate & $8.3 \pm 0.58$ & $9.7 \pm 0.58$ \\
\hline Calcium nitrate & $8.0 \pm 1.00$ & $9.5 \pm 0.50$ \\
\hline
\end{tabular}

Table 5: Selection of suitable nitrogen source for antibiotic production by cupplate method.

\begin{tabular}{|c|c|c|}
\hline \multirow[t]{2}{*}{ Malt extract $(\% \mathrm{w} / \mathrm{v})$} & \multicolumn{2}{|c|}{ Antibacterial activity (inhibition zone in $\mathrm{mm}$ ) } \\
\hline & Bacillus pumilus & Aeromonas formicans \\
\hline 1.0 & $16.5 \pm 0.76$ & $20.2 \pm 0.29$ \\
\hline 2.0 & $16.9 \pm 0.87$ & $20.6 \pm 0.58$ \\
\hline 3.0 & $17.6 \pm 0.76$ & $20.8 \pm 0.50$ \\
\hline 4.0 & $18.5 \pm 0.50$ & $21.4 \pm 0.29$ \\
\hline 5.0 & $16.5 \pm 0.50$ & $18.5 \pm 0.50$ \\
\hline
\end{tabular}

Table 6: Determination of optimum concentration of malt extract for antibiotic production by cup-plate method.

\begin{tabular}{|c|c|c|}
\hline \multirow[t]{2}{*}{$\mathrm{pH}$} & \multicolumn{2}{|c|}{ Antibacterial activity (inhibition zone in $\mathrm{mm}$ ) } \\
\hline & Bacillus pumilus & Aeromonas formicans \\
\hline 5.0 & $18.2 \pm 0.32$ & $21.2 \pm 0.29$ \\
\hline 6.0 & $20.5 \pm 0.50$ & $22.5 \pm 0.50$ \\
\hline 7.0 & $18.5 \pm 0.29$ & $21.5 \pm 0.50$ \\
\hline 8.0 & $16.6 \pm 0.78$ & $15.6 \pm 0.50$ \\
\hline
\end{tabular}

Table 7: Determination of optimum initial pH for antibiotic production by cup-plate method.

\begin{tabular}{|l|l|l|}
\hline Inoculum volume $(\% \mathbf{v} / \mathbf{v})$ & Antibacterial activity & (inhibition zone in $\mathbf{m m}$ ) \\
\hline & Bacillus pumilus & Aeromonas formicans \\
\hline 2.5 & $16.0 \pm 0.29$ & $17.2 \pm 0.15$ \\
\hline $\mathbf{5 . 0}$ & $\mathbf{2 2 . 0} \pm \mathbf{1 . 0 0}$ & $\mathbf{2 3 . 5} \pm \mathbf{0 . 5 0}$ \\
\hline 10.0 & $20.5 \pm 1.00$ & $22.5 \pm 0.50$ \\
\hline 15.0 & $20.2 \pm 1.76$ & $22.3 \pm 0.58$ \\
\hline 20.0 & $19.5 \pm 1.80$ & $20.8 \pm 0.76$ \\
\hline 25.0 & $18.7 \pm 1.15$ & $20.1 \pm 0.76$ \\
\hline 30.0 & $17.8 \pm 1.04$ & $18.8 \pm 1.04$ \\
\hline
\end{tabular}

Table 8: Determination of optimum inoculum volume for antibiotic production by cup-plate method.

\begin{tabular}{|l|l|l|}
\hline Incubation time (days) & \multicolumn{2}{|l|}{ Antibacterial activity } \\
\hline & Bacillus pumilus & Aeromonas formicans \\
\hline 1 & - & - \\
\hline 2 & $8.2 \pm 0.76$ & $8.6 \pm 0.29$ \\
\hline 3 & $14.6 \pm 0.29$ & $15.2 \pm 0.50$ \\
\hline $\mathbf{4}$ & $\mathbf{2 7 . 5} \pm \mathbf{0 . 5 0}$ & $\mathbf{2 6 . 5} \pm \mathbf{0 . 5 0}$ \\
\hline 5 & $22.0 \pm 1.00$ & $23.5 \pm 0.58$ \\
\hline 6 & $19.6 \pm 0.76$ & $20.6 \pm 0.50$ \\
\hline 7 & $17.3 \pm 0.50$ & $18.2 \pm 0.29$ \\
\hline 8 & $16.9 \pm 1.04$ & $16.8 \pm 0.76$ \\
\hline
\end{tabular}

Table 9: Determination of optimum incubation time for antibacterial production by cup-plate method.

\section{Conclusions}

Marine sediment samples from Visakhapatnam coast of Bay of Bengal, India were investigated to isolate 72 actinomycetes. After preliminary screening programme, 55 isolates that showed activity against both Gram-positive and Gram-negative bacteria by cross streak method were selected. Of these, 26 isolates showing significant intensity of inhibition were selected for extracellular antibiotic production studies by submerged fermentation using cup-plate method. Among the 26 active isolates, isolate DVR D4 showed potential antibacterial activity against the both Gram-positive and Gram-negative bacteria. In view of the differences observed in some of the phenotypic characteristics between our strain DVR D4 and the reference species Amycolatopsis $a l b a$, we felt our isolate DVR D4 should be included as a new variety of Amycolatopsis alba and be designated as Amycolatopsis alba var. nov DVR D4. The maximum activity of the antibiotic was achieved by the optimized production medium with optimized process parameters such as $5.0 \% \mathrm{v} / \mathrm{v}$ inoculum volume, $6.0 \mathrm{pH}$ and $96 \mathrm{~h}$ incubation.

\section{Acknowledgements}

Author Dasari is thankful to UGC, New Delhi, India for the financial assistance under UGC- Research Fellowships in Science for Meritorious Students.

\section{References}

1. Demain AL (1999) Pharmaceutically active secondary metabolites of microorganisms. Appl Microbiol Biotechnol 52: 455-463.

2. Fenical W, Baden D, Burg M, de Goyet CV, Grimes JD, et al. (1999) Marine derived pharmaceuticals and related bioactive compounds In: Fenical W, editor From monsoons to microbes: understanding the ocean's role in human health National Academic Press, Washington DC

3. Hopwood DA (2007) Therapeutic treasures from the deep. Nat Chem Biol 3 : 457-458.

4. Amador ML, Jimeno J, Paz-Ares L, Cortes-Funes H, Hidalgo H (2003) Progress in the development and acquisition of anti-cancer agents from marine source. Ann Oncol 14: 1607-1615. 
Citation: Venkata Ratna Ravi Kumar D, Murali Yugandhar N, Sri Rami Reddy D (2011) Screening of Antagonistic Marine Actinomycetes: Optimization of Process Parameters for the Production of Novel Antibiotic by Amycolatopsis Alba var. nov. DVR D4. J Microbial Biochem Technol 3: 092-098. doi:10.4172/1948-5948.1000058

5. Kumar S, Kannabiran K (2010) Diversity and optimization of process parameters for the growth of Streptomyces VITSVK9 sp isolated from Bay of Bengal India. J Nat Env Sci 1: 56-65.

6. Ramesh S, Narayanasamy M (2009) Screening of marine actinomycetes isolated from the Bay of Bengal, India for antimicrobial activity and industrial enzymes. World J Microbiol Biotechnol 25: 2103-2111.

7. Williams ST, Cross T (1971) Actinomycetes In: Booth C, editor. Methods in microbiology (Volume 4). Academic press, New York.

8. Holt JG, Krieg NR, Sneath PHA, Staley JT, Williams ST (1994) Bergey's manual of determinative bacteriology. ( $9^{\text {th }}$ edn), The Williams and Wilkins Co. Baltimore, Maryland, USA.

9. Williams ST, Goodfellow M, Alderson G, Wellington EMH, Sneath $\mathrm{PH}$, et al (1983) Numerical classification of Streptomyces and related genera. J Gen Microbiol 129: 1743-1813.

10. Goodfellow M, Brown A, Cai J, Chun J, Collins MD (1997) Amycolatopsis japonicum sp. nov., an actinomycete producing (S,S)-N,N'-ethylenediaminedisuccinic acid. Syst Appl Microbiol 20: 78-84.

11. Gordon RE, Barnett DA, Handerhan JE, Pang CHN (1974) Nocardia coeliaca, Nocardia autotrophica and the nocardin strain. Int J Syst Bacteriol 24: 54-63.

12. Wu C, Lu X, Qin M, Wang Y, Ruan J (1989) Analysis of menaquinone compound in microbial cells by HPLC. Microbiology 16: 176-178.

13. Collins MD (1985) Isoprenoid quinone analysis in classification and identification. In: Goodfellow M, Minnikin DE (editors) Chemical Methods in Bacterial Systematics. Academic Press, London.

14. Minnikin DE, O’Donnell AG, Goodfellow M, Alderson G, Athalye M, et al. (1984) An integrated procedure for the extraction of isoprenoid quinones and polar lipids. J Microbiol Methods 2: 233-241.

15. Hasegawa T, Takizawa M, Tanida S (1983) A rapid analysis for chemical grouping of aerobic actinomycetes. J Gen Appl Microbiol 29: 319-322.

16. Lechevalier HA, Lechevalier MP (1980) The chemotaxonomy of actinomycetes. In: Dietz A, Thayer DW, editors. Actinomycete Taxonomy (Society for Industrial Microbiology Special Publication Number 6). Society of Industrial Microbiology, Arlington.

17. Minnikin DE, Hutchinson IG, Caldicott AB, Goodfellow M (1980) Thin-layer chromatography of methanolysates of mycolic acid-containing bacteria. J Chromatogr 188: 221-233.

18. Maniatis T, Fritsch EF, Sambrook J (1982) Molecular cloning: a laboratory manual. Cold Spring Harbor Laboratory, Cold Spring Harbor, New York.

19. Marmur $\mathrm{J}$ (1961) A procedure for the isolation of deoxyribonucleic acid from microorganisms. J Mol Biol 3: 208-218.

20. Saitou N, Nei M (1987) The neighbor joining method: a new method for constructing phylogenetic trees. Mol Biol Evol 4: 406-425.

21. Ikuko K, Miho I, Keiichiro M, Aya N, Masahito $Y$, et al. (2011) Isolation of new hexapeptides-JBIR-39 and JBIR-40-from a marine sponge-derived Streptomyces sp. Sp080513SC-24. J Marine Sci Res Development 1: 1-4.

22. Ravi DVRK, Chakri S, Sowjanya M, Yugandhar NM, Sri DRR (2010) Medium optimization studies using response surface methodology for the production of Cellulase from banana fruit stalk using Cellulomonas uda NCIM 2353. Int J Biological Sci Engg 1: 119-127.

23. Benerji DSN, Ayyanna C, Rajini K, Srinivasa RB, Banerjee DRN, et al. (2010) Studies on physico-chemical and nutritional parameters for the production of Ethanol from mahua flower (Madhuca indica) using Saccharomyces cerevisiae -3090 through submerged fermentation (SmF). J Microbial Biochem Technol 2: $46-50$.

24. Sarat BI, Sita KK, Hanumantha RG (2010) Optimization of process parameters for the production of Lipase in solid state fermentation by Yarrowia lipolytica from niger seed oil cake (Guizotia abyssinica). J Microbial Biochem Technol 2: $28-33$

25. Sita KK, Narasimha RM (2010) Application of Doehlert experimental design for the optimization of medium constituents for the production of L-asparaginase from palm kernal cake (Elaeis guineensis). J Microbial Biochem Technol 2: 7-12.
26. Lakshmipathy D, Krishnan K (2010) Isolation and characterization of antagonistic actinomycetes from marine soil. J Microbial Biochem Technol 2 $1-6$.

27. Vuddaraju SP, Nikku MY, Chaduvula AIR, Dasari VRRK, Donthireddy SRR (2010) Application of statistical experimental designs for the optimization of medium constituents for the production of L-Asparaginase by Serratia marcescens. J Microbial Biochem Technol 2: 89-94.

28. Dasari VRRK, Donthireddy SRR, Nikku MY, Garapati HR (2009) Optimization of medium constituents for Cephalosporin $\mathrm{C}$ production using response surface methodology and artificial neural networks. J Biochem Tech 1: 69-74.

29. Usama B, Ayman D, Yousry G (2009) Optimization of submerged culture conditions for exo-polysaccharides production by Streptomyces nasri-UV 135 in bioreactor. J Microbial Biochem Technol 1: 43-46.

30. Kishore KG, Dasari VRRK, Garapati HR (2008) Production of Citric acid by Aspergillus niger MTCC 282 in submerged fermentation using Colocassia antiquorum. Res J Microbiol 3: 150-156

31. Yugandhar NM, Ravi DVRK, Prasanthi V, Kiran NK, Sri DRR (2008) Optimization of Pectinase production from Manihot utilissima by Aspergillus niger NCIM 548 using statistical experimental design. Res J Microbiol 3: 9-16.

32. Vaddiparthy SVR (1998) Studies on antagonistic actinomycetes from natura substrates of Andhra Pradesh, India and a diphenyl sulfone antibiotic produced by a new streptomycete - Streptomyces sulfonensis. Ph.D Thesis, College of Pharmaceutical Sciences, Andhra University, Visakhapatnam, Andhra Pradesh, India

33. Dasari VRRK, Donthireddy SRR, (2011) Amycolatopsis alba var. nov DVR D4 a bioactive actinomycete isolated from Indian marine environment. J Biochem Tech (Article in Press)

34. Bhadra R, Goswami SK, Majumdar SK (1973) Effect of different complex nutrients on neomycin production by Streptomyces fradiae. $\mathrm{H}$ folia Microbiologia 18: 300 .

35. Howard TD (1953) The production of neomycin by Streptomyces fradiae in synthetic media. Appl Microbiol 2: 103

36. Satish T, Mahalaxmi Y, Subba RCh, Suvarnalaxmi G, Sudhakar P, et al. (2008) Rifamycin B production pattern in Nocardia RSP-3 strain and influence of barbital on antibiotic production. Curr Trends Biotech Pharm 2: 173-181.

37. Sujatha P, Bapi RKVVSN, Ramana T (2005) Studies on a new marine streptomycete BT-408 producing polyketide antibiotic SBR-22 effective against methicillin resistant Staphylococcus aureus. Microbiol Res 160: 119-126.

38. Escalante L, Gonzalez R, Obregon AM, Sanchez S (1992) Carbon catabolite regulation of Gentamycin formation. J Antibiot 45: 465-469.

39. Syed AM, Safia A, Abduh H (2009) Antibiotic production by thermophilic Bacillus sp. SAT4. Pakistan J Pharm Sci 22: 339-345.

40. Demain AL (1989) Carbon source regulation of idiolite biosynthesis in actinomycetes. In: Shapiro S, editor. Regulation of actinomycetes. Boca Raton, FL: CRC Press

41. Gallo M, Katz E (1972) Regulation of secondary metabolite biosynthesis: catabolite repression of phenoxazinone synthase and actinomycin formation by glucose. J Bacteriol 109: 659-667.

42. Drew SW, Demain AL (1977) Effects of primary metabolites on secondary metabolism. Ann Rev Microbiol 31: 343-356.

43. Abdelghani T (2011) Production of antibacterial metabolite by strain no. 10/2 (S. albovinaceus) and media optimization studies for the maximum metabolite production. J Biotechnol Biotherapeut 1: 1-11.

44. Jain P, Pundir RK (2011) Effect of fermentation medium, pH and temperature variation on antibacterial soil fungal metabolite production. J Agri Technol 7 : 247-269.

45. Mudgetti RE (1986) Manual of industrial biotechnology. American society for microbiology, Washington DC.

46. Stanbury PF, Hall SJ, Whitaker A (1999) Principles of fermentation technology. $\left(2^{\text {nd }} e d n\right)$, Butterworth-Heinemann 